\title{
CARICA VIRALE, INTEGRAZIONE \\ ED ESPRESSIONE DEGLI ONCOGENI DI HPV I6: IMPLICAZIONI NELLA PROGRESSIONE DELLA PATOLOGIA CERVICALE
}

Venturoli S, Cricca M., Ambretti S., Gallinella G, Gentilomi G., Musiani M., Zerbini M.

D.M.C.S.S. Sez. di Microbiologia, Università di Bologna, Policlinico S.Orsola-Malpighi, Via Massarenti 9, 401 38 Bologna

La quasi totalità dei carcinomi cervicali è positiva al DNA di papillomavirus (HPV) ad alto rischio oncogeno, il genotipo prevalente è l'HPV 16. Nella progressione tumorale assume un ruolo rilevante l'integrazione del genoma virale nel genoma cellulare. L'integrazione avviene frequentemente in seguito all'interruzione della ORF E2. Poiché la proteina E2 controlla negativamente l'espressione delle oncoproteine virali E6/E7, quando la relativa ORF è interrotta si ha una sovraespressione di E6/E7. Oltre all'integrazione virale e all'espressione dei messaggeri virali E6/E7 anche la carica virale potrebbe essere un parametro virologico importante nella patogenesi della progressione tumorale, seppure dati discordanti esistano in letteratura.

Per lo studio di questi indicatori virologici, relativamente al genotipo 16, sono stati allestiti saggi di Real time PCR quantitativi utilizzando lo strumento Rotor-Gene e la chimica SYBR Green. La carica virale è stata normalizzata rispetto ad un gene housekeeping (E6/GAPDH) e lo stato fisico è stato stabilito in base al rapporto E2/E6. L'analisi dei messaggeri virali è stata effettuata con tecnica NASBA e tecniche di Real time PCR.

Le tecniche allestite sono state impiegate per l'analisi di 123 esfoliati cervicali provenienti da pazienti con lesioni di basso e alto grado.

Dall'analisi dei risultati è emersa una percentuale di DNA allo stato misto in lesioni di basso grado del $30 \%$ dimostrando che l'integrazione può essere un processo precoce nella patogenesi della progressione tumorale, inoltre è stata rintracciata una associazione tra carica virale e grado della lesione che ha consentito di stabilire un valore soglia per individuare le pazienti con lesioni di basso grado a maggior rischio neoplastico. Campioni provenienti da pazienti con lesioni di alto grado e DNA allo stato episomiale con elevata carica virale hanno mostrato una attiva produzione di messaggeri virali suggerendo che un numero elevato di genomi virali possa essere sufficiente per innescare la trasformazione cellulare anche in assenza di integrazione. 